\title{
Research Paper \\ Effect of 8 Weeks of High Intensity Interval Training (HIIT) With and Without Calorie Restriction on Gene Expression of Caspase-3 and Caspase-9 Proteins in Male Rats
}

\author{
Mohammadreza Zarali ${ }^{1} \odot{ }^{*}$ Zaher Etemad $^{1} \odot$, Kamal Azizbeigi $^{1} \odot$, Pouran Karimi ${ }^{2}$ \\ 1. Department of Exercise Physiology, School of Physical Education and Sport Sciences, Sanandaj Branch, Islamic Azad University, Sanandaj, Iran. \\ 2. Department of Clinical Biochemistry, School of Medicine, Tabriz University of Medical Sciences, Tabriz, Iran
}

\begin{tabular}{|c|c|}
\hline $\begin{array}{l}\text { Use your device to scan } \\
\text { and read the article online }\end{array}$ & Crtation: Zarali M, Etemad Z, Azizbeigi K, Karimi P. [Effect of 8 Weeks of High Intensity Interval Training (HIIT) With and \\
\hline 口. & Without Calorie Restriction on Gene Expression of Caspase-3 and Caspase-9 Proteins in Male Rats (Persian)]. Journal of Arak \\
\hline & University of Medical Sciences (JAMS). 2020; 23(3):300-313. https://doi.org/10.32598/JAMS.23.3.5960.1 \\
\hline 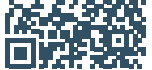 & d cilhttps://doi.org/10.32598/JAMS.23.3.5960.1 \\
\hline
\end{tabular}

$0(0)$

Article Info:

Received: 04 Sep 2019

Accepted: 12 Nov 2019

Available Online: 01 Aug 2020

Key words:

High intensity interval

training, Caloric

restriction, Caspase

\section{A B STRACT}

Background and Aim Apoptosis or programmed death is active biological process and reversible that the balance between growth and cell death in various tissues, particularly myocardial tissue is essential role. The aim of this study was the effect of 8 weeks High Intensity Interval Training (HIIT) with and without food restriction on gene expression of Caspase 3 and 9 in rats.

Methods \& Materials This study was experimental multi group design with control group which conducted on 30 rats with two months old male. Subjects were divided in to five homogenous groups including base control, control, caloric restriction, interval exercise training and caloric restriction+interval exercise training. Training groups five sessions in weeks were participated in interval exercise training for 8 weeks. The level of gene expression of the proteins Caspase 3 and 9 was evaluated by Real Time-PCR. Dates were analyzed using the 1-way ANOVA at the level of $(P<0.05)$.

Ethical Considerations The protocol of this study was approved by the Medical Committee of Sanandaj University of Medical Sciences (Code: IR.MYK.REC.1397.5022).

Results The results showed that the training group had a significant decrease in gene expression of Caspase 3 in comparison with caloric restriction+exercise training $(P<0.05)$. Also, exercise training and exercise training+caloric restriction significantly decrease in the gene expression of Caspase 9 compared to caloric restriction, base control and control $(P<0.05)$ and significantly decrease in the gene expression of Caspase 3 compared to base control and control $(\mathrm{P}<0.05)$.

Conclusion According to the results, it seems that high intensity interval training with and without calorie restriction provides the necessary adaptations to inhibit or stop apoptosis induced by aerobic exercise.

\section{Extended Abstract}

\section{Introduction}

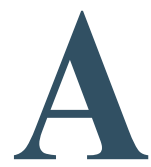

poptosis is a biologically active and reversible process that plays a key role in regulating the balance between cell growth and death in various tissues, especially the myocardium. This process begins with the compression and fragmentation of chromatins and the condensation of the cellular cytoplasm and ends with the crumpling of the cell nucleus and membranes and the production of vacuoles containing apoptotic particles [1-3]. Apoptosis occurs through the intracellular and extracellular pathways $[1,2,4]$.

* Corresponding Author:

Zaher Etemad, PhD.

Address: Department of Exercise Physiology, School of Physical Education and Sport Sciences, Sanandaj Branch, Islamic Azad University, Sanandaj, Iran. Tel: +98 (918) 1741523

E-mail: zetemad2002@yahoo.com 
Table 1. Descriptive characteristics of the rats

\begin{tabular}{cccc}
\hline Groups & Body Weight & Heart Weight & Ratio of Heart Weight to Body Weight \\
\hline Basic control & $173.37 \pm 11.96$ & $0.556 \pm 0.06$ & $3.10 \pm 0.24$ \\
\hline Control & $399.13 \pm 18.67$ & $1.04 \pm 0.07$ & $2.62 \pm 0.17$ \\
\hline Calorie restriction & $323.03 \pm 7.69$ & $1.06 \pm 0.05$ & $3.20 \pm 0.22$ \\
\hline Exercise & $345.26 \pm 8.97$ & $1.20 \pm 0.06$ & $3.49 \pm 0.21$ \\
\hline Exercise and calorie restriction & $322.93 \pm 10.41$ & $1.10 \pm 0.02$ & $3.40 \pm 0.13$ \\
\hline
\end{tabular}

The internal pathway, as the most important pathway for apoptosis, is associated with changes in mitochondrial permeability and release of apoptotic agents. Molecular events of apoptosis are determined by the balance between preand anti-apoptotic specific regulatory proteins. In the meantime, $\mathrm{Bax}$ and $\mathrm{Bcl} 2$ proteins are involved as major proteins in the formation of apoptosis and mitochondrial apoptotic messages. The aim of the present study was to investigate the effect of 8 weeks of High-Intensity Interval Training (HIIT) with and without calorie restriction on gene expression of caspase- 3 and caspase- 9 proteins in male rats.

\section{Materials and Methods}

The present research was an experimental study performed in a field and laboratory method in which the effect of 8 weeks of high-intensity interval training with and without calorie restriction on gene expression of caspase- 3 and caspase-9 proteins in male rats was investigated. Considering the suitable conditions of the animal model for the present study, 30 two-month-old male Wistar rats were purchased from the Pasteur Institute of Iran. After familiarizing the rats with the laboratory environment, they were divided into five groups of six ("basic control", "control", "calorie restriction", "exercise", and "exercise and calorie restriction") (Table 1). In order to control the baseline variables and to determine the reference group, the "baseline control" group underwent surgery at the beginning of the research period using the specified laboratory method. All rats were placed on a treadmill for 14 days under a training program.

The subjects in the "control" and "exercise" groups freely used standard food and water during the study period. To determine the amount of food consumed by the "calorie restriction" and "exercise" groups, along with the application of calorie restriction to them, the amount of food consumed by the other subjects was measured daily and the restricted groups received $50 \%$ of the food consumed by the other groups.

\section{Results}

The results of one-way ANOVA showed that there was a significant difference between the expression of myocardial caspase- 3 protein in male rats $(\mathrm{P}=0.001)$. Also, the results of Tukey post hoc test showed that the "basic control" and "control" groups had a significant increase in the expression of myocardial caspase- 3 protein compared to the "exercise

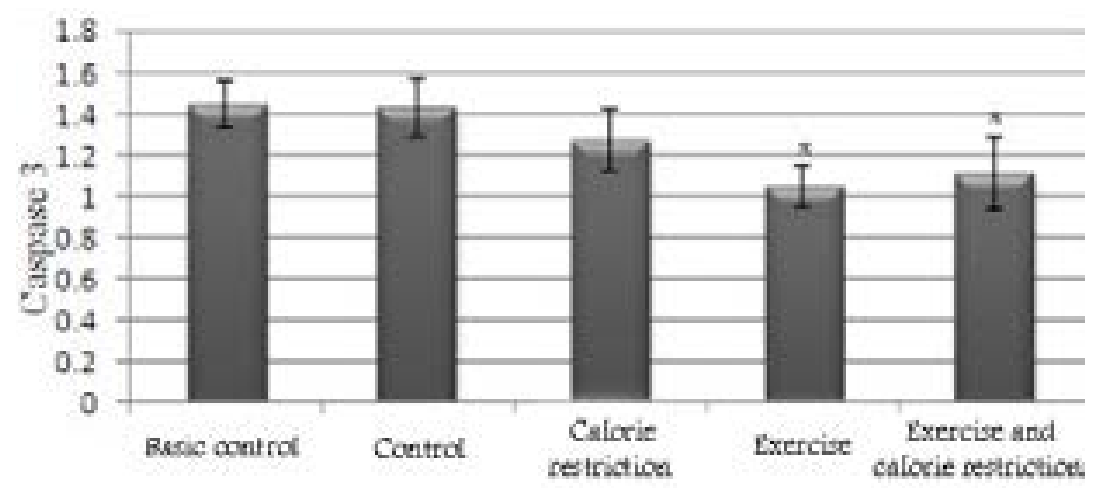

Figure 1. Changes in caspase-3 in different groups

*significant difference compared to basic control, control and calorie restriction groups. 


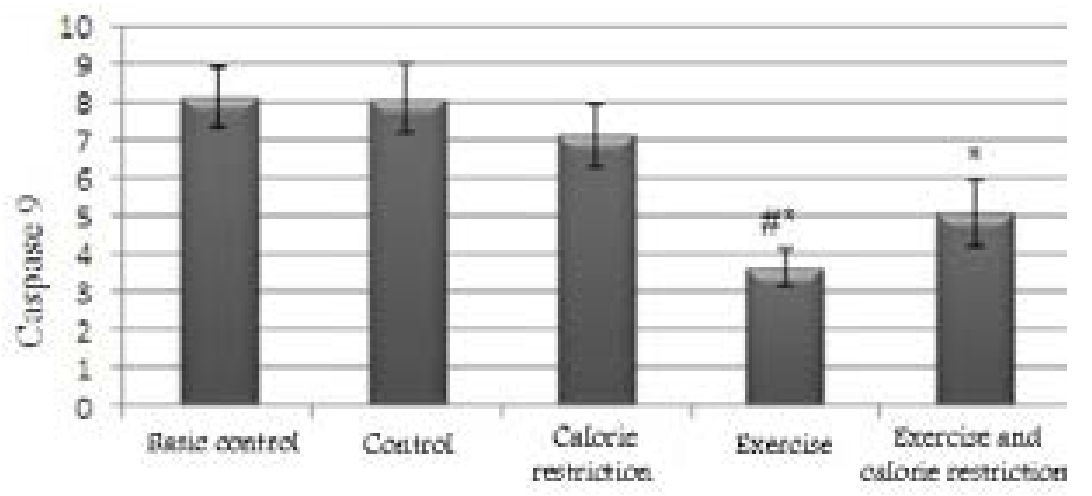

Figure 2. Changes in caspase-9 in different groups

*significant difference compared to basic control, control and calorie restriction groups; \#significant difference compared to exercise and calorie restriction groups.

and calorie restriction" and "exercise" groups $(\mathrm{P}<0.05)$. The results of one-way ANOVA showed that there was a significant difference between the expression rate of myocardial caspase- 9 protein in male rats $(\mathrm{P}=0.001)$.

Also, the results of Tukey post hoc test showed that the "basic control", "control" and "calorie restriction" groups had a significant increase in the expression of myocardial caspase-9 protein compared to the "exercise and calorie restriction" and "exercise" groups $(\mathrm{P}<0.05)$. On the other hand, the "exercise" group had a significant decrease in the expression of myocardial caspase-9 protein compared to the "exercise and calorie restriction" group $(\mathrm{P}<0.05)$ (Figures 1 and 2$)$.

\section{Discussion}

Although the exact mechanisms of exercise-induced apoptosis are unclear, there are many possible hypotheses that need further investigation. One of the important hypotheses in this regard is that during exercise, muscle metabolism increases, which leads to the production of ROS [5]. High quantities of ROS can produce oxidative damage and thus lead to apoptosis via the internal pathway [15]

It has been reported that a significant decrease in caspase-3 protein expression following aerobic exercise was associated with a decrease in pre-apoptotic factors such as Bax protein expression and $\mathrm{Bax}$ to $\mathrm{Bcl} 2$ ratio as well as a significant increase in Bcl2 anti-apoptotic protein. This decrease in mitochondrial apoptotic potential following aerobic exercise in elderly rats may be associated with decreased release of apoptotic agents such as cytochrome c and Apafl into skeletal muscle, which significantly reduced caspase-3 expression [14].
In the internal pathway, mitochondria and endoplasmic reticulum play a major role in this process, in which the role of mitochondria in apoptosis is the most important and have been focused in many studies $[5,16,17]$. Under stressful conditions, factors such as glucocorticoids, ROS, nitrogen monoxide, chemotherapy drugs, radiation, reduced growth stimulants, and cytokines cause changes in mitochondrial permeability by causing stress; and cytochrome $\mathrm{c}$ which is located in the inner membrane of the mitochondria and interstitial space, is released into the cytosol and binds to apoptosis-activating protease factor 1 (Apaf-1) inside the release cytosol to form a compound called dATP. This compound then induces apoptosis by activating procaspase- 9 , caspase-9, and caspase-3 [18]. The most important step in controlling this pathway is the release of cytochrome $\mathrm{c}$. Cell death pathway inhibitory proteins such as Bcl-2 and Bcl-XL inhibit the release of cytochrome $\mathrm{c}$ and thus play a role [19].

\section{Conclusion}

According to the results, it seems that high-intensity interval exercise with and without calorie restriction provides the necessary adaptations to inhibit or stop apoptosis caused by aerobic exercise. In addition, in this study, the contribution of caspase- 8 , especially caspase- 6 , and even bad protein as pathways for possible interactions was not investigated. Therefore, activation of caspase- 3 might have originated externally, which was one of the limitations of the present study.

\section{Ethical Considerations}

\section{Compliance with ethical guidelines}

The protocol of this study was approved by the Medical Committee of Sanandaj University of Medical Sciences (Code: IR.MYK.REC.1397.5022). 


\section{Funding}

The present paper was extracted from the $\mathrm{PhD}$. thesis of the first author, Department of Exercise Physiology, School of Physical Education and Sport Sciences, Sanandaj Branch, Islamic Azad University.

Authors' contributions

All authors contributed in preparing this article.

\section{Conflicts of interest}

The authors declared no conflict of interest. 
This Page Intentionally Left Blank 


\title{
تأثير ^ هفته تمرين تناوبى با شدت بالا (HIIT) با و بدون محدوديت كالرى بر بيان ثن يروتيئنهاى

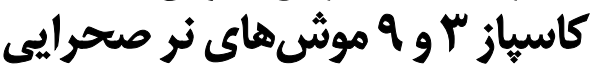

\author{
محمدرضا زارعلى' • "ظاهر اعتماد' •، كمال عزيزبيكى' •، يوران كريمى'

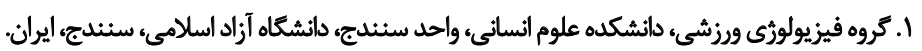

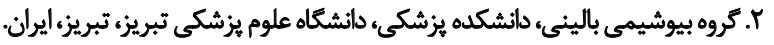

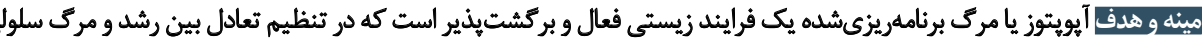

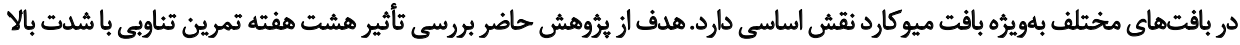
(HIIT)

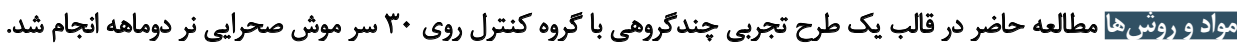

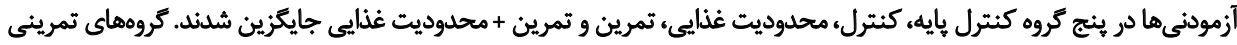

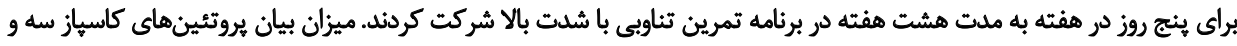

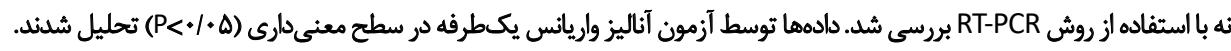

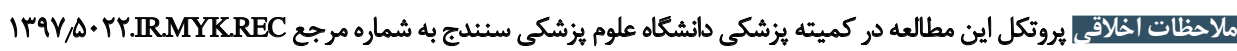
به تاييد رسيده است.

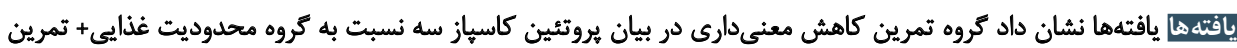

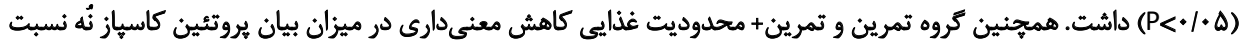

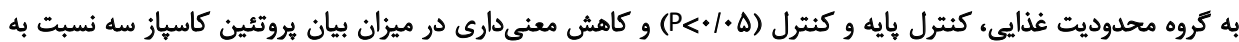

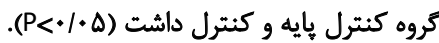

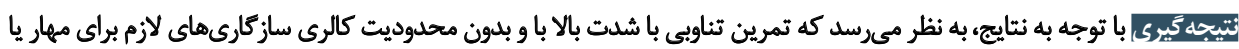

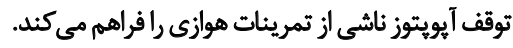

اطلاعات مقاله:

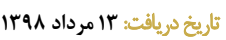

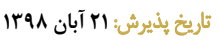

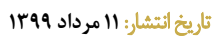

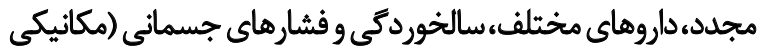

مقدمه

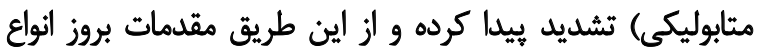

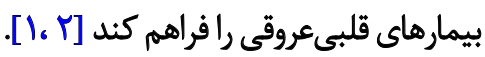
آيويتوز يا مرك برنامهريزىشده يك فرايند زيستى فعال و اين فرايند فيزيولوريايى از طريق دو مسير داخل و خارج سلولى بالى

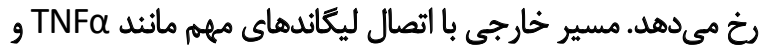

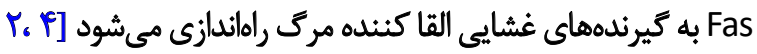

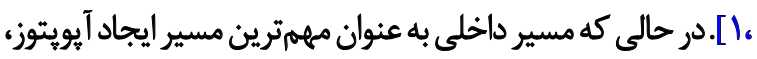

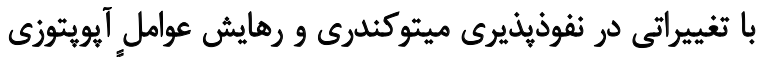

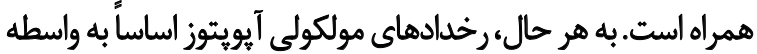

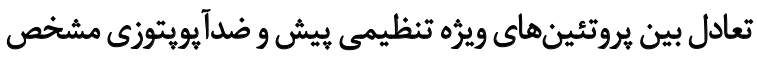

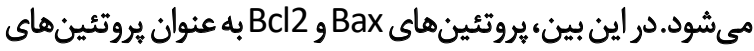

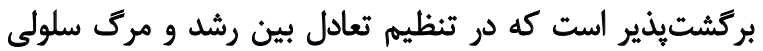

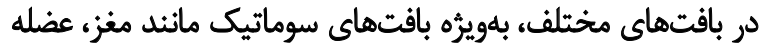

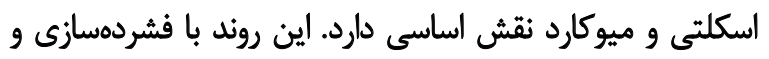

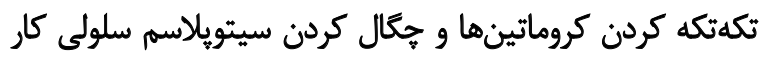

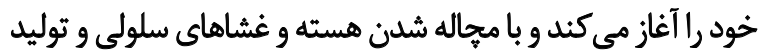

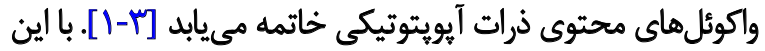

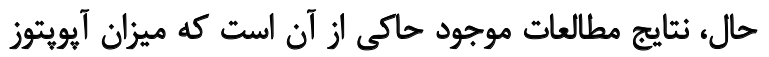

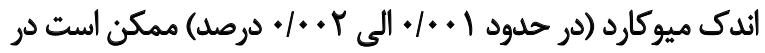

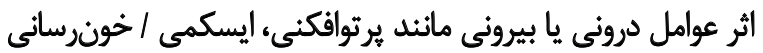


باعث كاهش غيرمعنى دار يروتئين كاسياز ب در موشهاى صحرايى

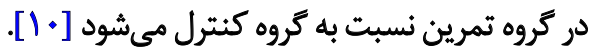

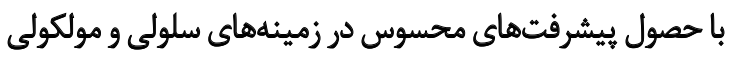

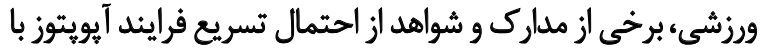

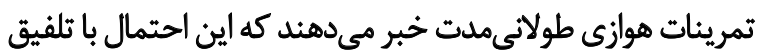

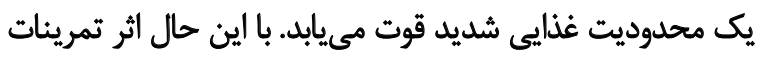

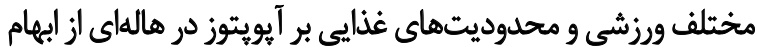

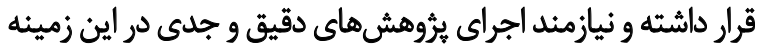

با توجه به اينكه تفاوت شدت ومدت تمرينات هوازى مورداستفاده

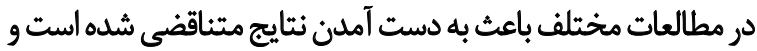

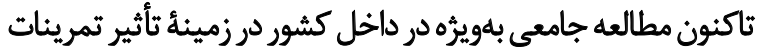

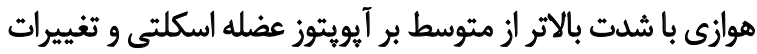

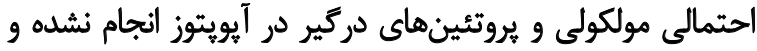

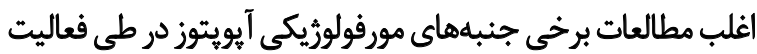

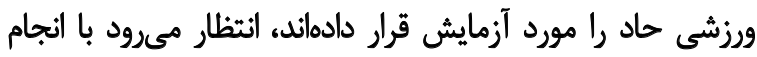

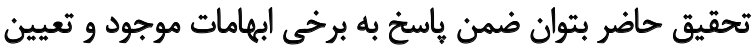

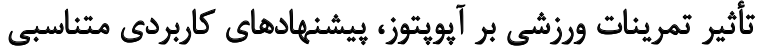

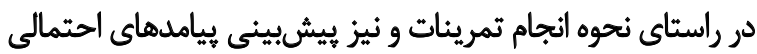
ناشى از تمرين همراه با محدوديت كالرى ارائه داد.

$$
\text { مواد و روش كها }
$$

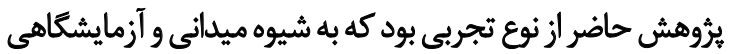

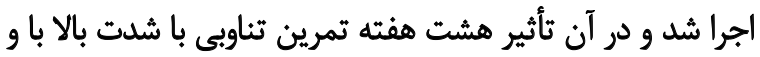

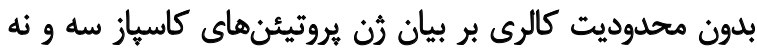

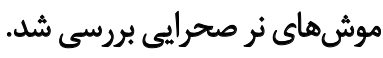
با توجه به شرايط مناسب مدل حيوانى براى مطالعه حاضر،

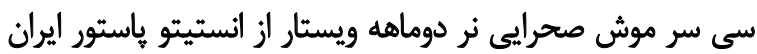

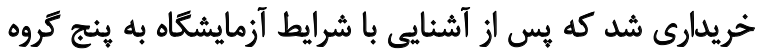

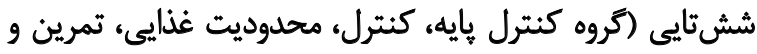

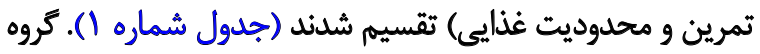

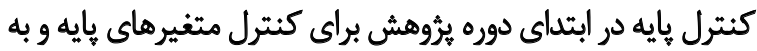

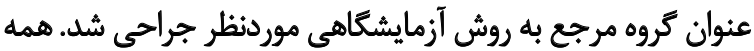

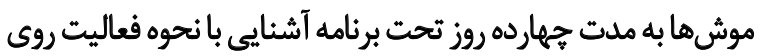

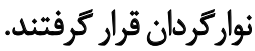

آزمودنىهاى كروه كنترل و تمرين به صورت آزادانه از

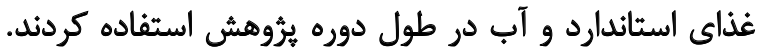

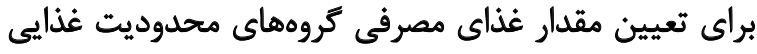

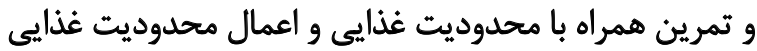

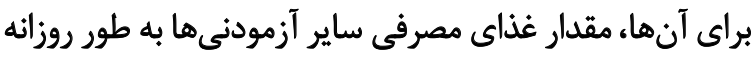

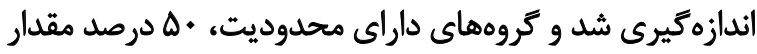
غذاي مصرفى ساير كروهها را دريافت كردند.
اصلى در شكل كيرى آيويتوز و يامهاي آيويتوز ميتوكندريايى دركير

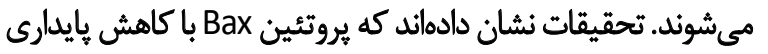

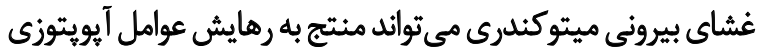

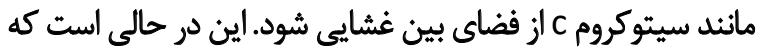

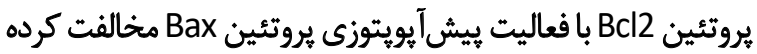

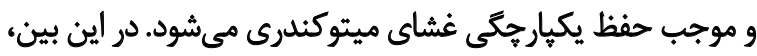

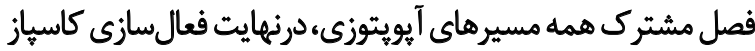

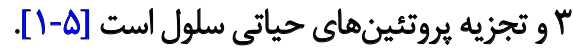

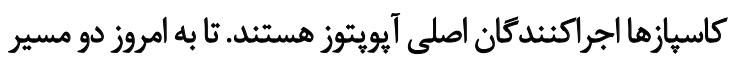

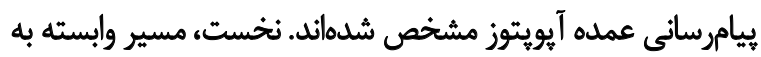

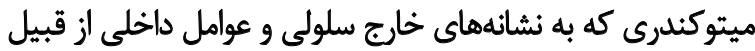

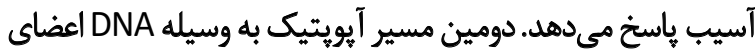

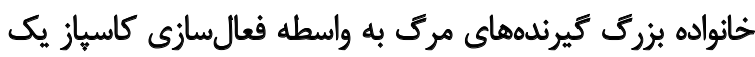

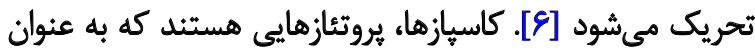

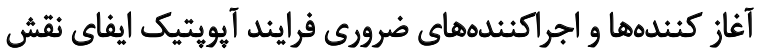

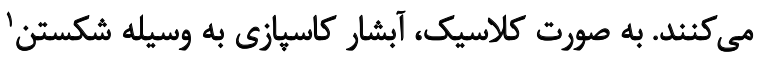

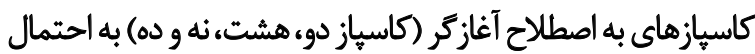

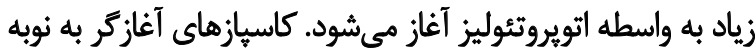

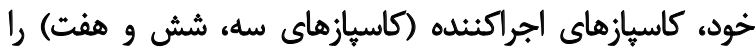

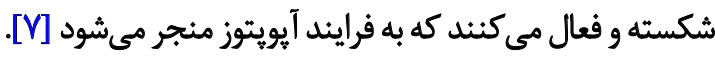
كاسياز سه يكى از مهمترين يروتئازهاى اجراكنيده در مسير

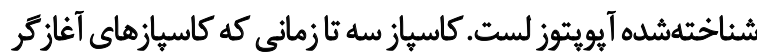

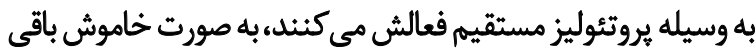

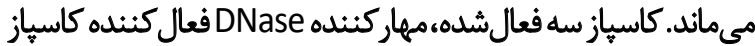

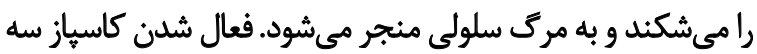

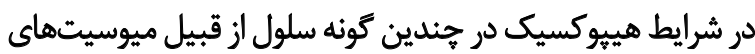

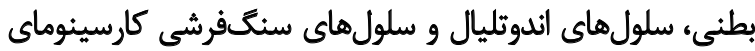
ريه نشان داده شده است [^]ـ. برخى از محققين معتقدند كه بروز فشار در حين فعاليتهاى

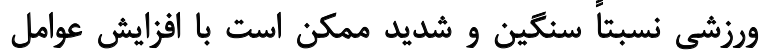

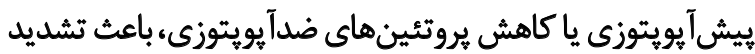

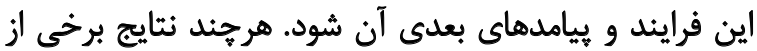

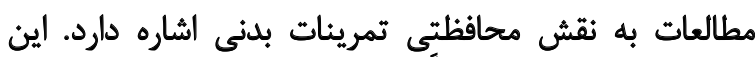

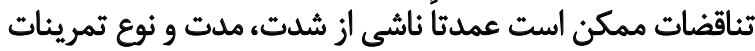

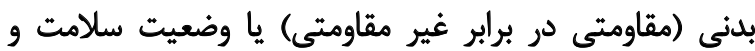
آمادكى آزمودنى هاى مورد مطالعه باشد.

تبريزى و همكاران نشان دادئد دوازده هفته برنامه تمرين هوازى

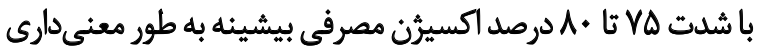

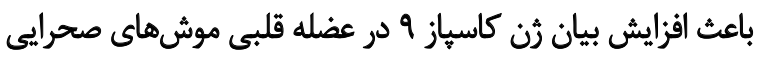

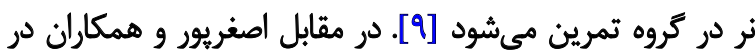

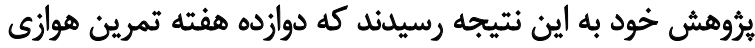


جدول ا. مشخصات توصيفى موشها

\begin{tabular}{|c|c|c|c|}
\hline نسبت وزن قلب به وزن بلن & وزن ق تلب & وزن بلن & كروه \\
\hline$m / l \cdot \pm \cdot / M$ & $. / \Delta \Delta \& \pm .1 .8$ & $1 \mathrm{rr} / \mathrm{r} \pm 11 / \mathrm{Q}$ & كتّرل يايه \\
\hline$r / g Y \pm . / T V$ & $V \cdot P \pm \cdot 1 \cdot V$ & พจด/พIINEV & 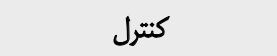 \\
\hline$M / T \cdot \pm \cdot M$ & $1 / .8 \pm \cdot 1 \cdot 0$ & $M T / \cdot r \pm V / e q$ & هحلوديث كالرياييى \\
\hline$r / f q \pm \cdot / r)$ & $1 / 7 \cdot \pm \cdot 1 \cdot 8$ & $M E A / T E \pm N A Y$ & تمرين \\
\hline$r / 4 \cdot \pm \cdot / N$ & $V / 1 \cdot \pm * / \cdot r$ & Mrr/ar $\pm 1+/ F 1$ & تمرين و محلوديت كالريايى \\
\hline
\end{tabular}

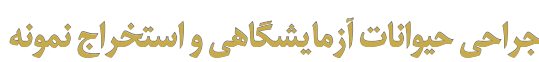

همه آزمودنىها طبق برنامه از بيش تعيينشده و با با استفاده از

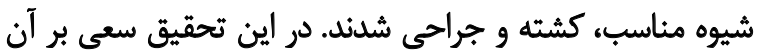

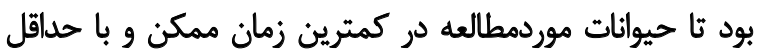

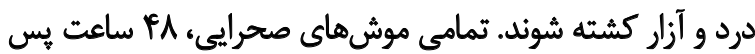

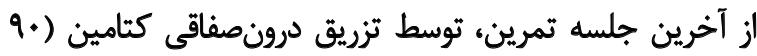

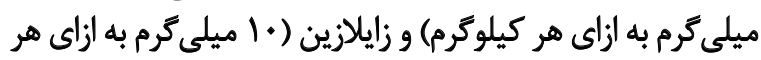

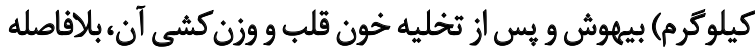

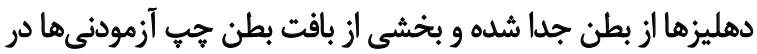

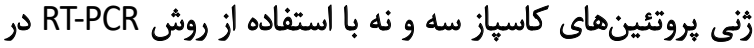

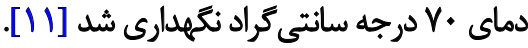

CDNA $\because$ Lw

طبق دستورالعمل كيت (Fermentas, Canada) يك ميكروليتر

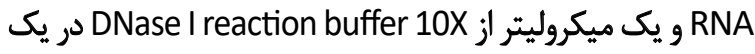

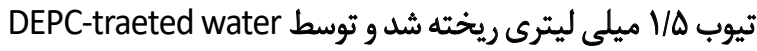

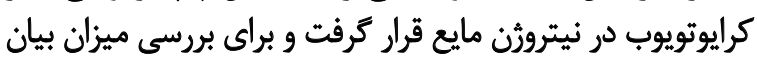

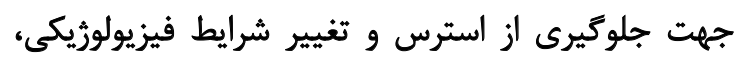

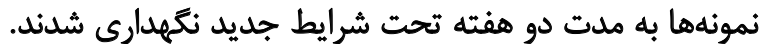

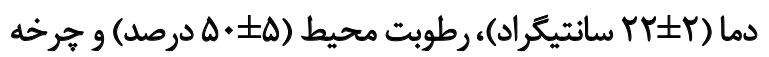

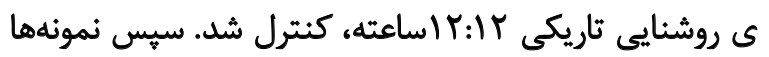

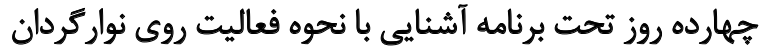

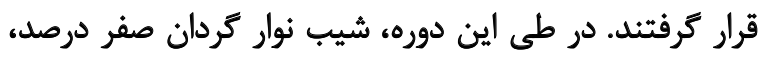

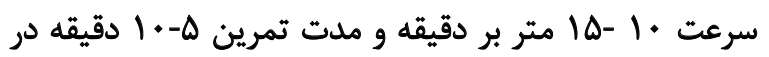

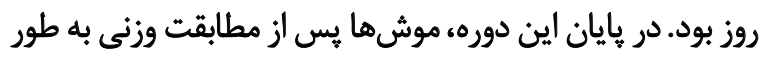

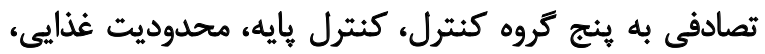

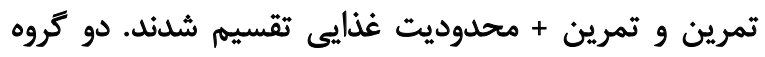

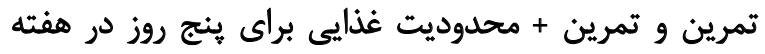

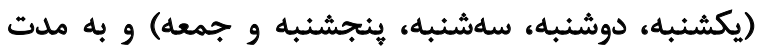

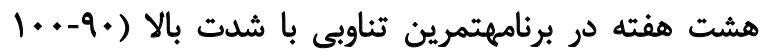

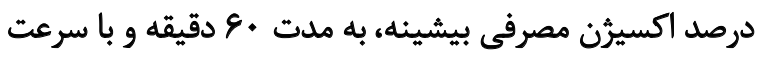

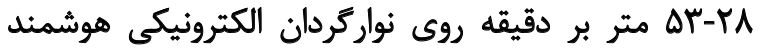

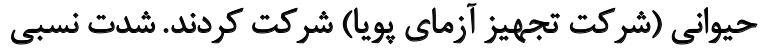

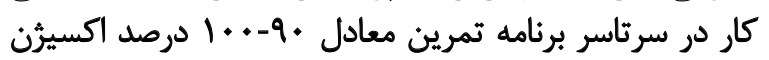

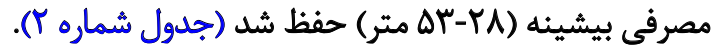

جدول r. برنامه تمرين ثناوبى با شدت بالا

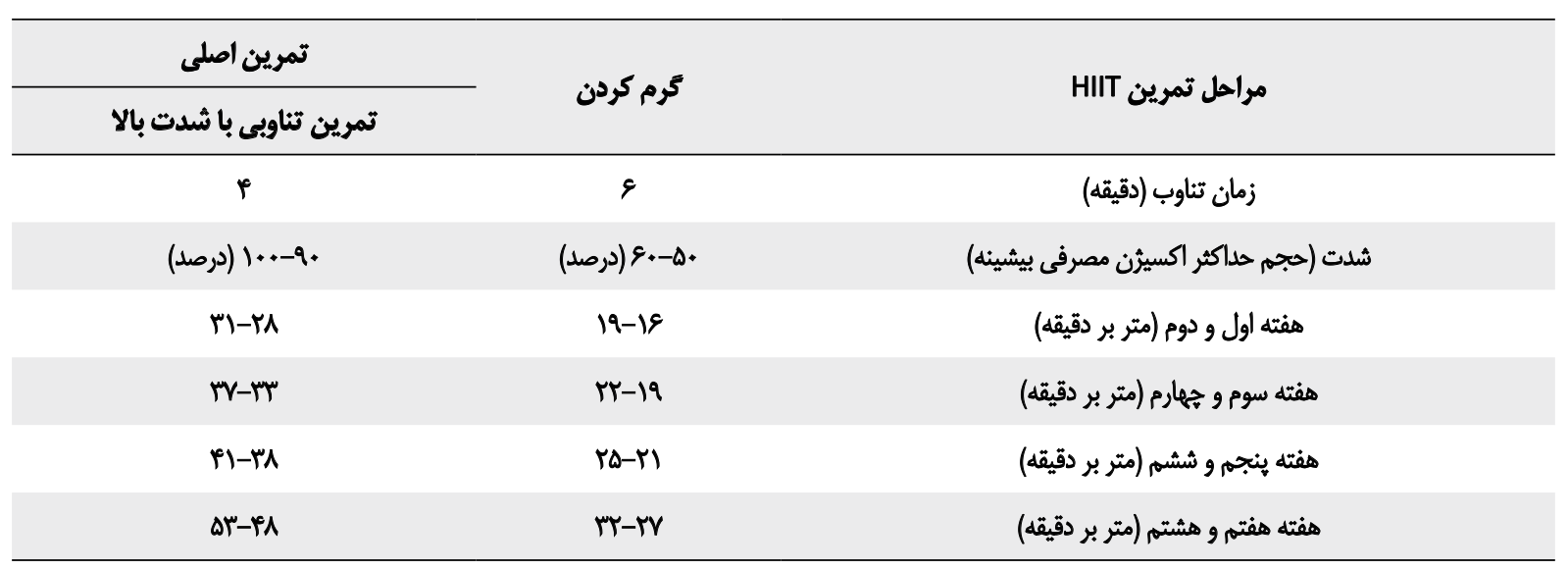


Genes

Primer sequence Product

length (bp)

Caspase 3

F: 5'GGAGCTTGGAACGGTACGCT3' R:5'AGTCCACTGACTTGCTCCCA3'

F:5' CGAGCTGTTCAGGCCCCATA3'

R: 5'CGCAGAAACGAAGCCAGCAT3

Caspase9

$\beta$-actin

F: 5'CTCTGTGTGGATCGGTGGCT3' R:5'GCAGCTCAGTAACAGTCCGC3 in

111

ITA
متصل شده و نور فلورسنت ساطع مي كند. به عنوان بلانك از تيوبى

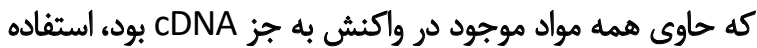

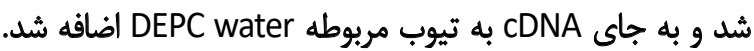

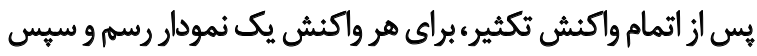

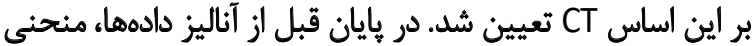

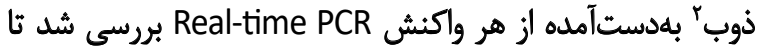

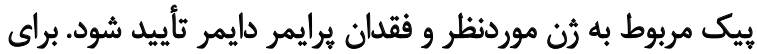

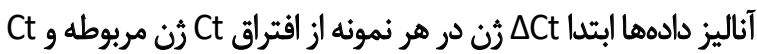

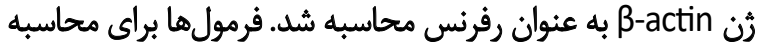

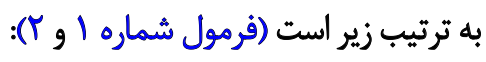

\section{$\Delta C T=C T$ target $-C T$ reference}

\section{$\Delta \Delta C T=\Delta C T$ test sample $-\Delta C T$ control sample}

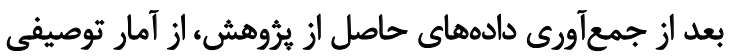

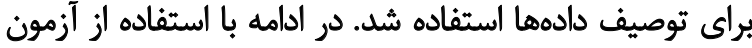

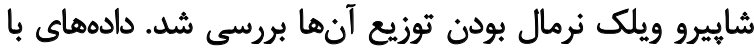

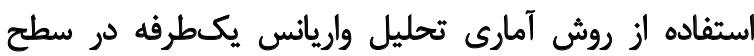

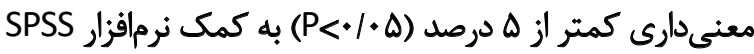

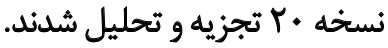

\section{ياقتثهنه}

نتايج آزمون تحليل واريانس يكسطرفه نشان داد تفاوت معنى دارى

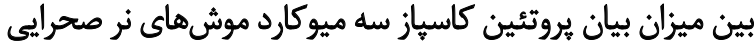

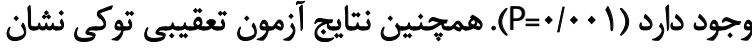

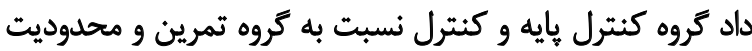

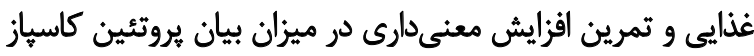

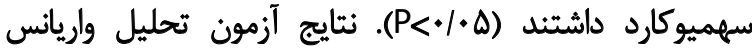
يكطرفه نشان داد تفاوت معنى دارى بين ميزان بيان يروتئين كاسياز

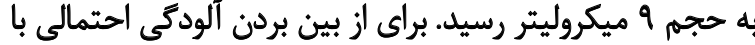

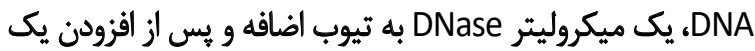

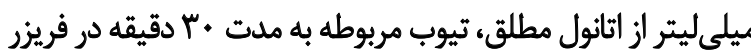

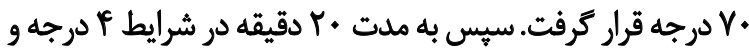

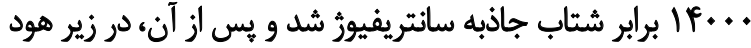

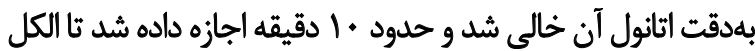
تبخير شود. به تيوب يك ميكروليتر treated water DEPC

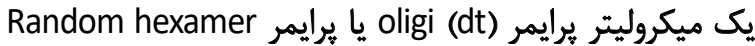

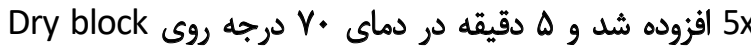

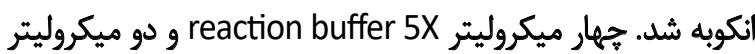

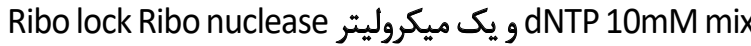
Transcription Inhibitor

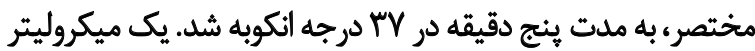

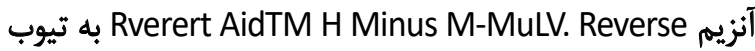

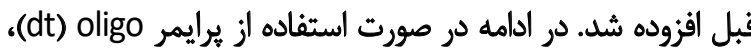

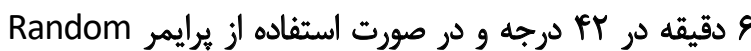

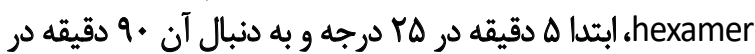

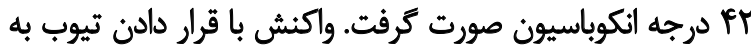

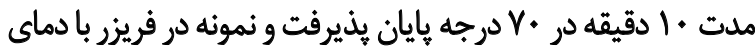

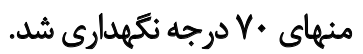

Real-time PCR

براى اندازميرى ميزان بيان رنى يروتئهاى موردنظر، از

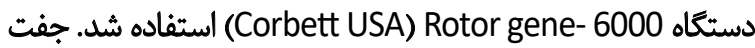

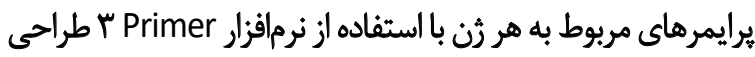

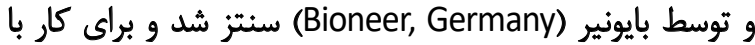

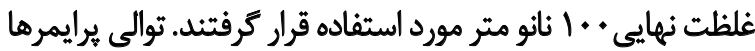

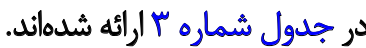
Long واكنشها بر مبناي استفاده از رنك Syber green انجام شد. رنك Syber green 


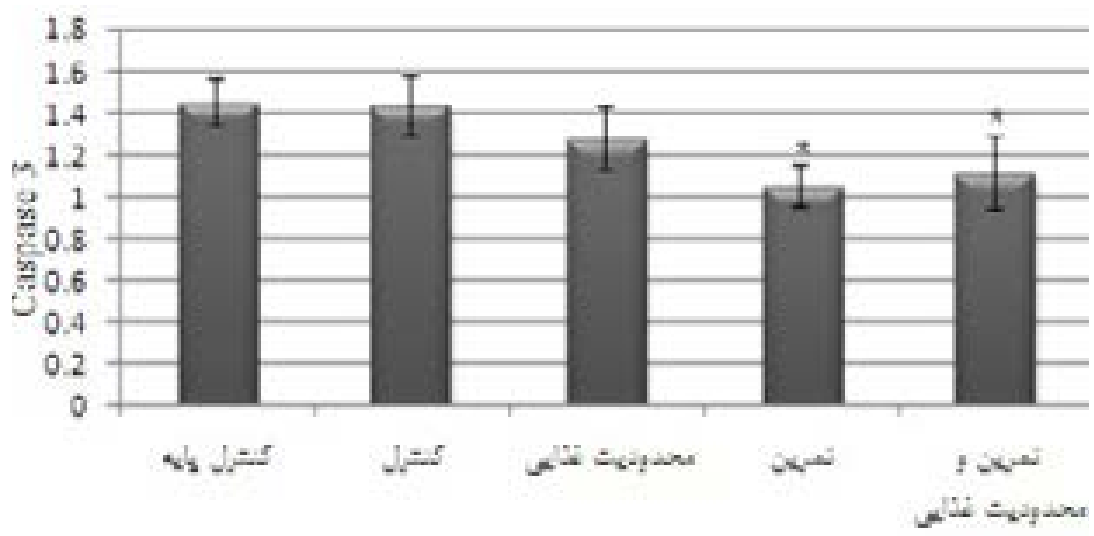

تصوير ا. تغييرات كاسياز سه در كروههاي مختلف (* تفاوت معنى دار نسبت به كروه كنترل يايه، كنترل و محدوديت غذايي)

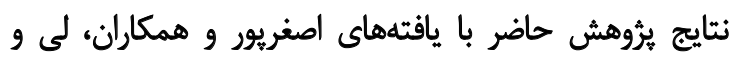

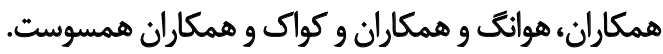

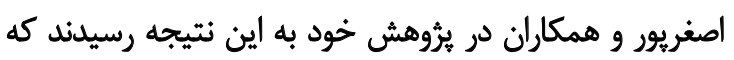

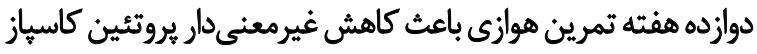

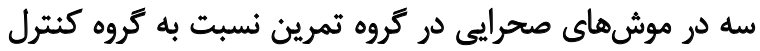

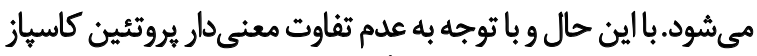

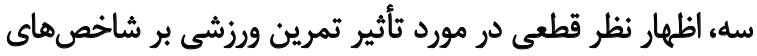

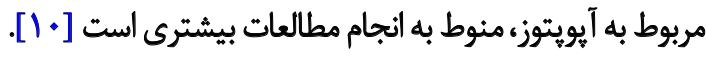
لى و همكاران مطالعهائ را براى بررسى اثر تمرين ورزشي بر

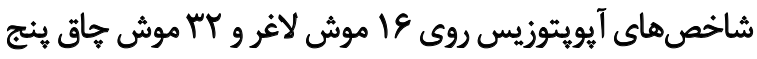

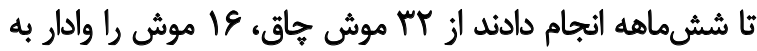

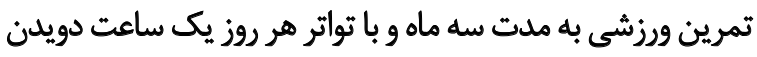

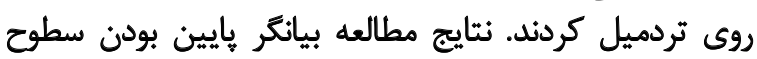

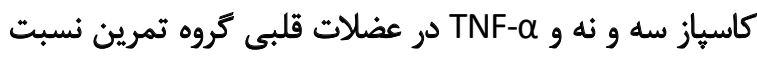

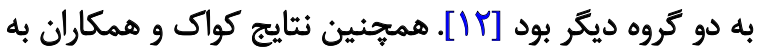

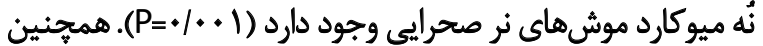

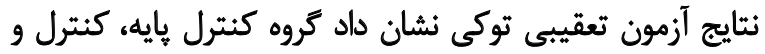

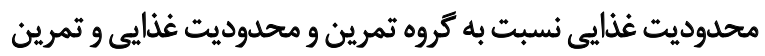

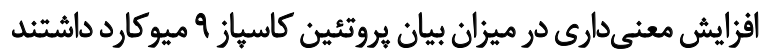

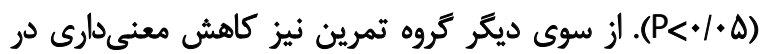

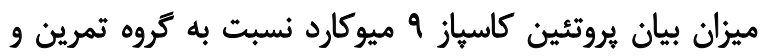

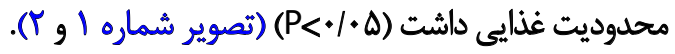

$\stackrel{+}{*}$

نتايج يثوهش حاضر نشان داد كروه تمرين كاهش معنى دارى

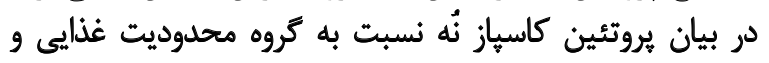

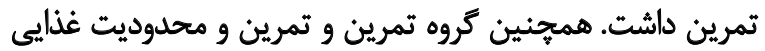

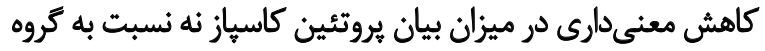

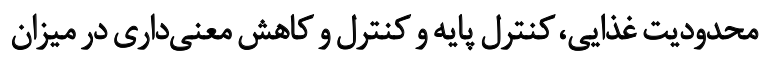

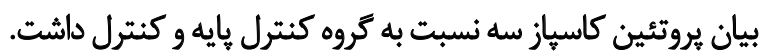
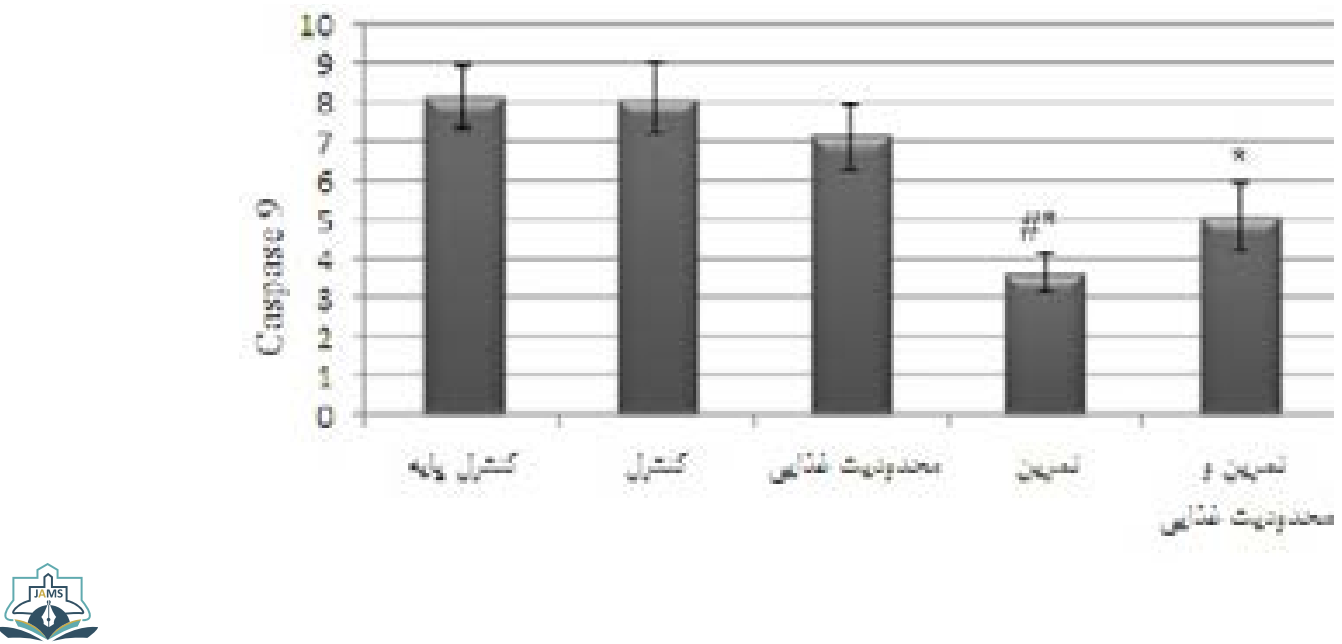

تصوير ب. تغييرات كاسياز نه در كروههاي مختلف (

و محدوديت غُذايى) 


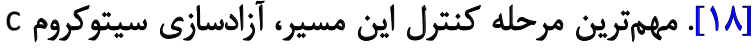

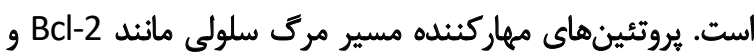

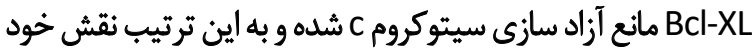

, إيفا مى كنئد [19].

برخى از مطالعات اشاره دارند كه محدوديت غذايى يا كالريكى و

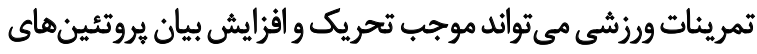

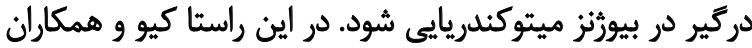

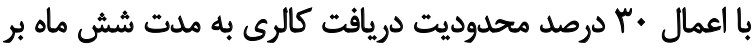

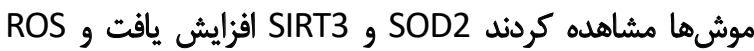

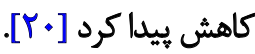

با اين حال و بر خلاف نتايج مطالعات مذكور، برخى از يُروهشها

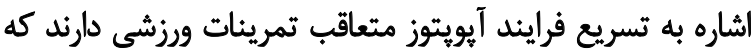

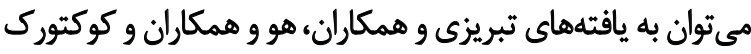

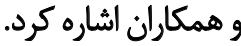

هو و همكار ان نشان دادند كه بيان يروتئين كاسياز سه در ميوكارد

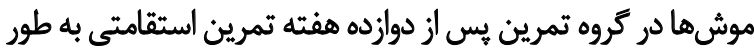

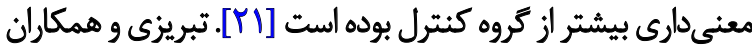

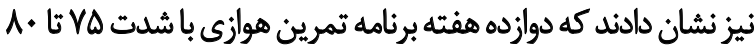

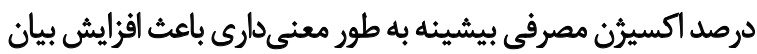

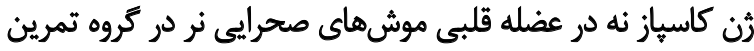

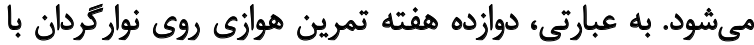

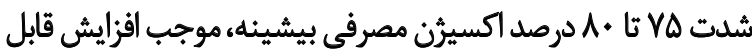

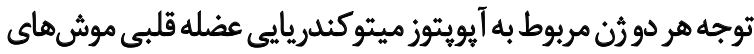

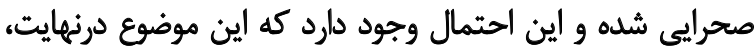

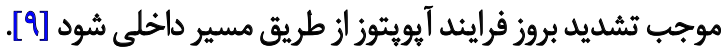
يكى از علتهاى مغايرت يافتهاى تبريزى و همكاران با نتايج

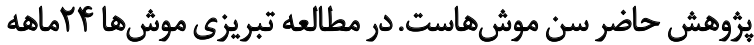

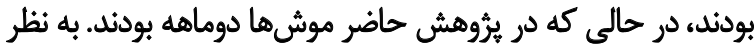

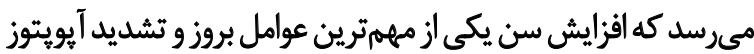

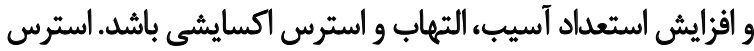

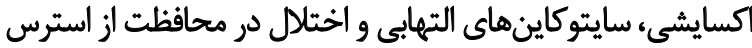

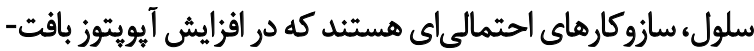

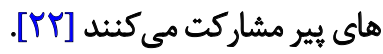

كوكتورى و همكاران ياسخ آيويتوزيسى را نسبت به فعاليت

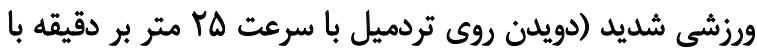

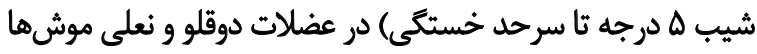

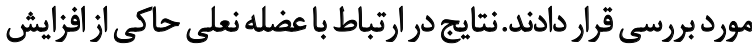

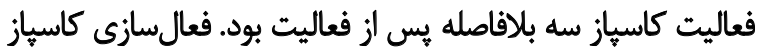

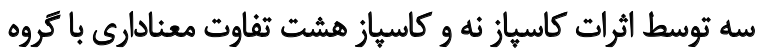

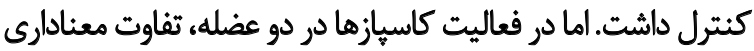

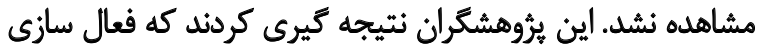

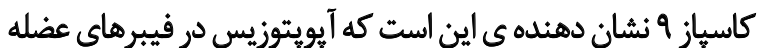

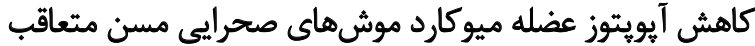

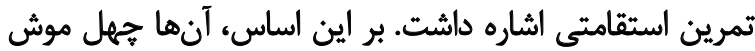

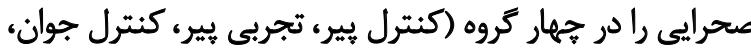

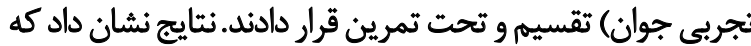

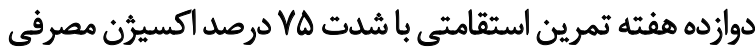

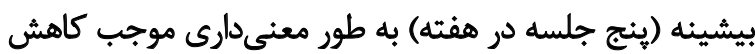

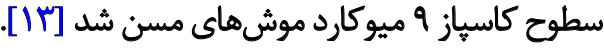
هوانك و همكاران با در نظر كرفتن اينكه آيويتوزيس قلبى در

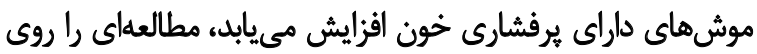

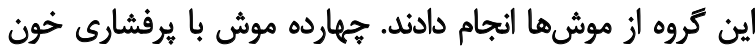

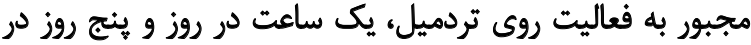

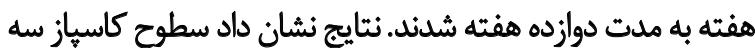

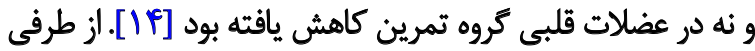

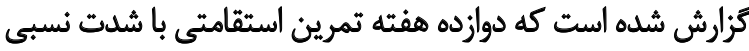

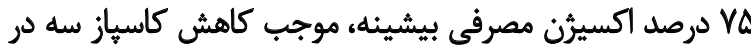

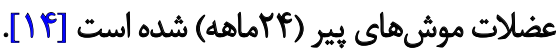

اكرجه مكانيسمهاى دقيق آيويتوزيس ناشى از فعاليت ورزشى به

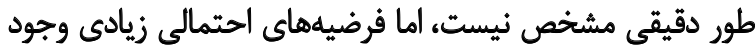

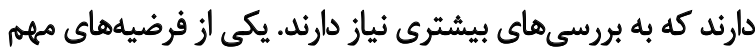

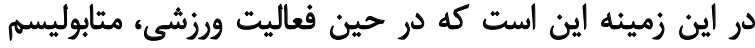

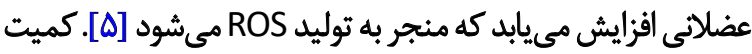

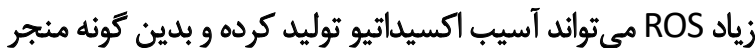

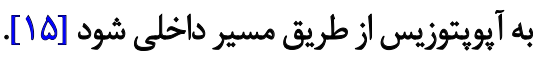

كزارش شده است كه كاهش قابل توجه بيان يروتئين كاسياز

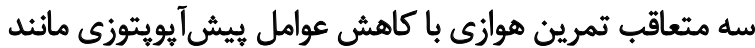

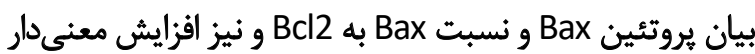

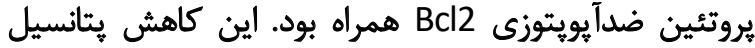

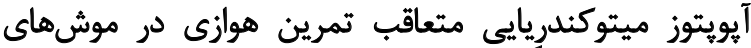

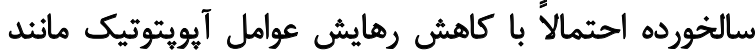

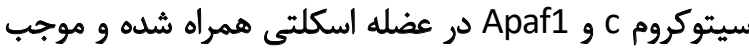
كاهش معنى دار بيان كاسياز سه شده است [1F]

در مسير داخلى، ميتوكندرى و رتيكلوم اندويلاسميك محوريت إينايت

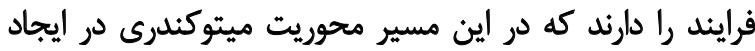

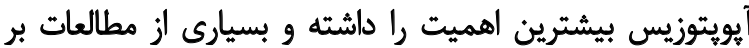

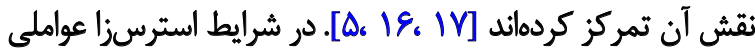

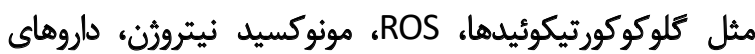

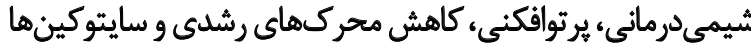

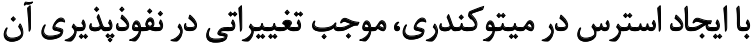

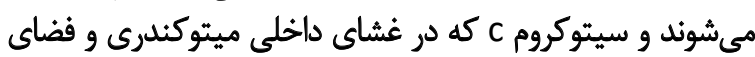

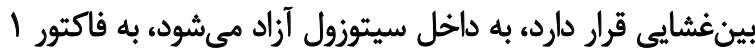

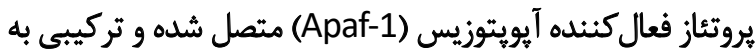

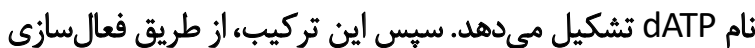

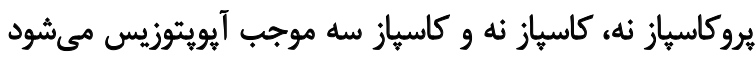


اين روند با افزايش بيان BCl-2 سركوب مىشود [YN]. نتيجنيَّيرى

با توجه به نتايج، به نظر مىرسد تمرين تناوبى با شدت بالا باو

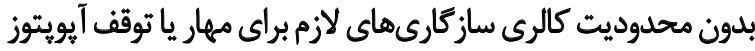

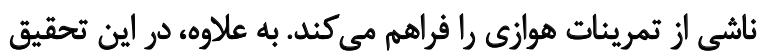

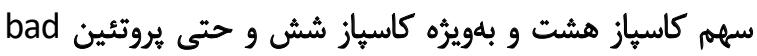

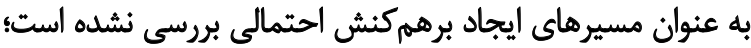

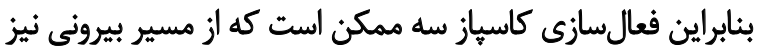
منشأ كرفئه باشد كه از محدوديتهائ تحان تحقيق حاضر است.

ماحظات اخلاقى

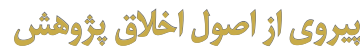

يروتكل اين مطالعه در كميته يزشكى دانشكاه علوميزشكى سنندج به شماره مرجع IR.MYK.REC.1397.5022 به تأييد رسيده است.

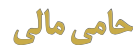

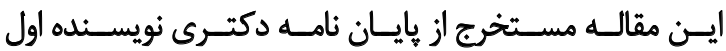

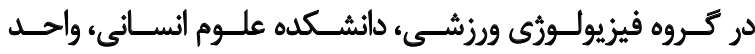

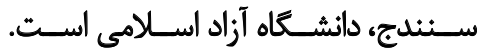

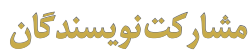

تمامى نويسئدكان در نكارش اين مقاله مشاركت داشتهاند.

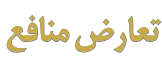

نويسندكان مقاله هيج كونه تعارضى در منافع اعلام نكردند.
نعلى، وابسته به مكانيسم داخلى و فعال سازى مكانيسم خارجى از

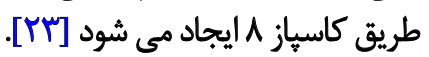

كوئيندرى و همكاران نيز اشاره به كاركرد حفاظتى تمرين

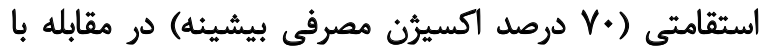

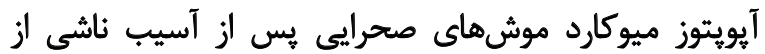

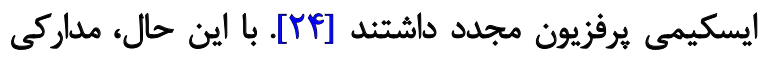

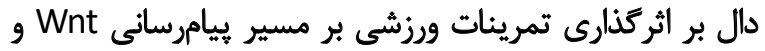

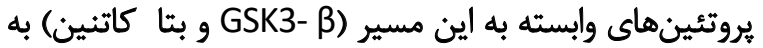

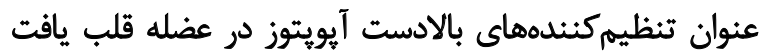

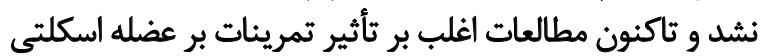

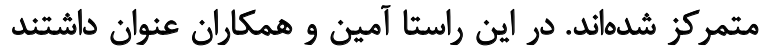

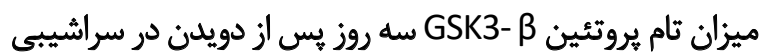

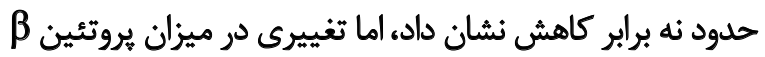

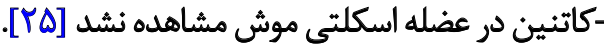

افزايش سطوحTNF-

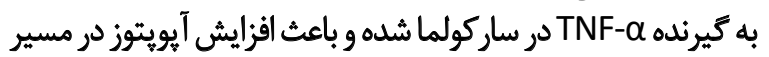

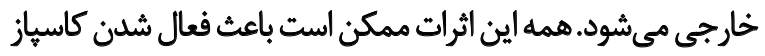

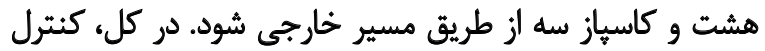

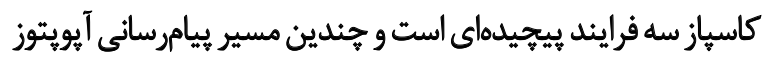

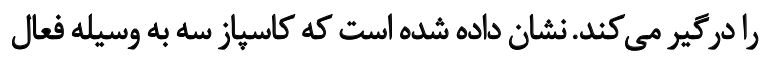

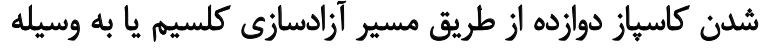

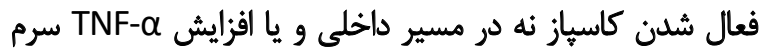

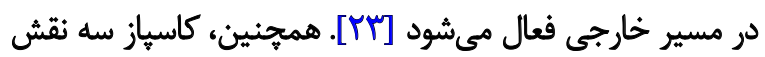

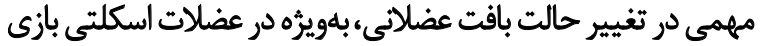

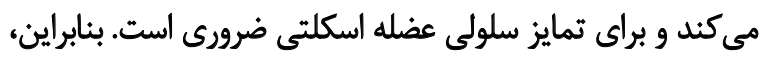

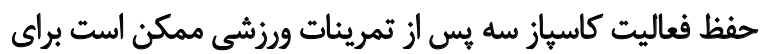

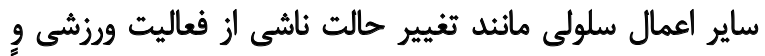

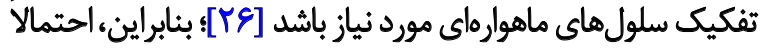

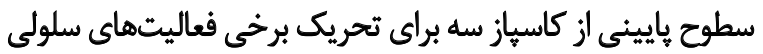
و ترميم يا رشد بافت متعاقب تمرين ورزشى مناسب باسي باشد.

سازوكار آيويتوزيس با واسطه رتيكلوم اندويلاسميك

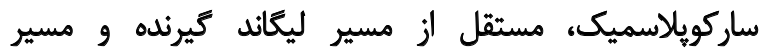

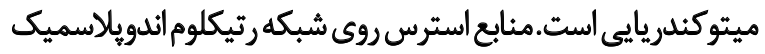

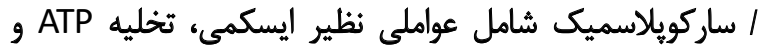

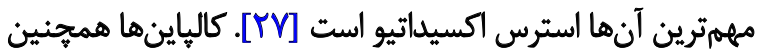

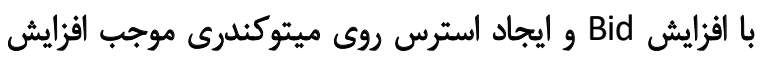
رهاسازى سيتوكروم C و درنهايت كاسياز نه مي مشوند [TA]

استرس روى شبكه رتيكلوم اندويلاسميك / ساركويلاسميك

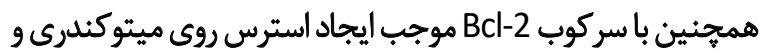

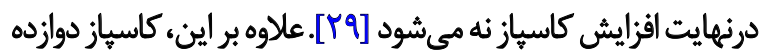

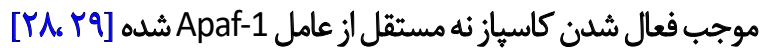

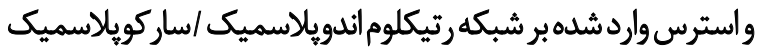
موجب افزايش استرس اكسيداتيو و تغييرات ميتوكندرى مي شئود كه 


\section{References}

[1] Favaloro B, Allocati N, Graziano V, Ilio CD, Laurenzi V.D. Role of Apoptosis in disease. Aging. 2012; 4(5):330-49. [DOI:10.18632/aging.100459] [PMID] [PMCID]

[2] Kwak HB. Effects of aging and exercise training on apoptosis in the heart. J of Exer Rehabi. 2013; 9(2):219-22. [DOI:10.12965/jer.130002] [PMID] [PMCID]

[3] Lee Y, Min K, Talbert EE, Kavazis AN, Smuder AJ, Willis WT, et al. Exercise protects cardiac mitochondria against ischemia reperfusion injury. MedSci Sports Exerc. 2012; 44(3):397-405. [DOI:10.1249/ MSS.0b013e318231c037] [PMID]

[4] Phaneuf S, Leeuwenburgh C. Apoptosis and exercise. Med Sci Sports Exerc. 2001; 33(3):393-6. [DOI:10.1097/00005768200103000-00010] [PMID]

[5] Peterson JM, Bryner RW, Sindler A, Frisbee JC, Alway SE. Mitochondrial apoptotic signaling is elevated in cardiac but not skeletal muscle in the obese Zucker rat and is reduced with aerobic exercise. J Appl Physiol. 2008; 105(6):1934-43. [DOI:10.1152/japplphysiol.00037.2008] [PMID] [PMCID]

[6] Zhong $\mathrm{N}$, Chen $\mathrm{H}$, Zhao Q, Wang $\mathrm{H}, \mathrm{Yu}$ X, Eaves AM, et al. Effects of griseofulvin on apoptosis through caspase-3- and caspase-9-dependent pathways in K562 leukemia cells: An in vitro study. Curr Ther Res Clin Exp. 2010; 71(16):384-97. [DOI:10.1016/S0011-393X(10)80004-9]

[7] Rodríguez-Berriguete G, Galvis L, Fraile B, de Bethencourt FR, Martínez-Onsurbe $P$, Olmedilla $G$, et al. Immunoreactivity to caspase-3, caspase-7, caspase-8, and caspase- 9 forms is frequently lost in human prostate tumors. Hum Pathol. 2012; 43(2):229-37. [DOI:10.1016/j.humpath.2011.04.024] [PMID]

[8] Harada H, Hiraoka M, Kizaka-Kondoh S. Antitumor effect of TAToxygendependent degradation-caspase-3 fusion protein specifically stabilized and activated in hypoxic tumor cells. Cancer Res. 2002; 62(7):2013-8. [PMID]

[9] Javid Tabrizi N, Bashiri J, Narimani Rad M. [Effect of 12 weeks of treadmill aerobic training on cytochrome $\mathrm{C}$ and Caspase- 9 gene expression in cardiac muscle of male rats (Persian)]. Qom Univ Med Sci J. 2017; 11(6):1-9. http://journal.muq.ac.ir/article-1-869-en.html

[10] Siahkohian M, Asgharpour-arshad M, Bolboli L, Jafari A, Sheikhzadeh hesari F. [Effect of 12- weeks aerobic training on some indices of skeletal muscle apoptosis in male rats (Persian)]. Med J Tabriz Univ Med Sci Health Serv. 2018; 39(6):35-43. https://www.sid.ir/fa/journal/ViewPaper.aspx?id=359071

[11] Marzetti E, Lawler JM, Hiona A, Manini T, Seo AY, Leeuwenburgh C. Modulation of age-induced apoptotic signaling and cellular remodeling by exercise and calorie restriction in skeletal muscle. Free Radic Biol Med. 2008; 44(2):160-8. [DOI:10.1016/j.freeradbiomed.2007.05.028] [PMID]

[12] Lee SD, Shyu WC, Cheng IS, Kuo CH, Chan YS, Lin YM, et al. Effects of exercise training on cardiac apoptosis in obese rats. Nutr Metab Cardiovasc Dis. 2013; 23(6):566-73. [DOI:10.1016/j. numecd.2011.11.002] [PMID]

[13] Kwak HB, Song W, Lawler JM. Exercise training attenuates ageinduced elevation in $\mathrm{Bax} / \mathrm{Bcl}-2$ ratio, apoptosis, and remodeling in the rat heart. FASEB J. 2006; 20(6):791-3. [DOI: 10.1096/fj.05-5116fje] [PMID]

[14] Huang Ch, Lin TJ, Chen ChCh, Lin WT. Endurance training accelerates exhaustive exercise-induced mitochondrial DNA deletion and apoptosis of left ventricle myocardium in rats. Eur J Appl Physiol. 2012; 107(6):697. 706. [DOI:10.1007/s00421-009-1177-4] [PMID]
[15] Rastogi RP, Rajeshwar R, Sinha RP. Apoptosis: Molecular mechanisms and pathogenicity. EXCLI J. 2009; 8:155-88.

[16] Marzetti E, Privitera G, Simili V, Wohlgemuth SE, Aulisa L, Pahor M, et al. Multiple pathways to the same end: mechanisms of myonuclear apoptosis in sarcopenia of aging. ScientificWorldJournal. 2010; 10:340-9. [DOI:10.1100/tsw.2010.27] [PMID] [PMCID]

[17] Viña J, Gomez-Cabrera MC, Borras C, Froio T, Sanchis-Gomar F Martinez-Bello VE et al. Mitochondrial biogenesis in exercise and in ageing. Adv Drug Deliv Rev. 2009; 61(14):1369-14. [DOI:10.1016/j. addr.2009.06.006] [PMID]

[18] Wang ZB, Liu YQ, Cui YF. Pathways to caspase activation. Cell Biol Int. 2005; 29(7):489-96. [DOI:10.1016/j.cellbi.2005.04.001] [PMID]

[19] Youle RJ, Strasser A. The BCL-2 protein family: Opposing activities that mediate cell death. Nat Rev Mol Cell Biol. 2008; 9(1):47-59. [DOI:10.1038/nrm2308] [PMID]

[20] Qiu X, Brown K, Hirschey MD, Verdin E, Chen D. Calorie restriction reduces oxidative stress by SIRT3-mediated SOD2 activation. Cell Metab. 2010; 12(6):662-7. [DOI:10.1016/j.cmet.2010.11.015] [PMID]

[21] Ho TJ, Huang CC, Huang CY, Lin WT. Fasudil, a Rho-kinase inhibitor protects against excessive endurance exercise training-induced cardiac hypertrophy, apoptosis and fibrosis in rats. Eur J Appl Physiol. 2012; 112(8):2943-55. [DOI:10.1007/s00421-011-2270-z] [PMID]

[22] Song W, Kwak HB, Lawler JM. Exercise training attenuates age-induced changes in apoptotic signaling in rat skeletal muscle. Antioxid Redox Signal. 2006; 8(3-4):517-28. [DOI:10.1089/ars.2006.8.517] [PMID]

[23] Koçtürk S, Kayatekin BM, Resmi H, Açikgöz O, Kaynak C, Ozer E. The apoptotic response to strenuous exercise of the gastrocnemius and solues muscle fibers in rats. Eur J Appl Physiol. 2008; 102(5):515-24. [DOI:10.1007/s00421-007-0612-7] [PMID]

[24] Quindry JC, Miller L, McGinnis G, Kliszczewicz B, Irwin JM, Landram M, et al. Ischemia reperfusion injury, KATP channels, and exercise-induced cardioprotection against apoptosis. J Appl Physiol. 2012; 113(3):498506. [DOI:10.1152/japplphysiol.00957.2011] [PMID] [PMCID]

[25] Amin H, Vachris J, Hamilton A, Steuerwald N, Howden R, Arthur ST. GSK3 $\beta$ inhibition and LEF1 upregulation in skeletal muscle following a bout of downhill running. J Physiol Sci. 2014; 64(1):1-11. [DOI:10.1007/ s12576-013-0284-5] [PMID]

[26] McMillan EM, Graham DA, Rush JW, Quadrilatero J. Decreased DNA fragmentation and apoptotic signaling in soleus muscle of hypertensive rats following 6 weeks of treadmill training. J Appl Physiol (1985). 2012; 113(7):1048-57. [DOI:10.1152/japplphysiol.00290.2012] [PMID]

[27] Rasheva VI, Domingos PM. Cellular responses to endoplasmic reticulum stress and apoptosis. Apoptosis. 2009; 14(8):996-1007. [DOI:10.1007/s10495-009-0341-y] [PMID]

[28] Szegezdi E, Fitzgerald U, Samali A. Caspase-12 and ER-stress-mediated apoptosis: The story so far. Ann N Y Acad Sci. 2003; 1010:186-94. [DOI:10.1196/annals.1299.032] [PMID]

[29] Zhang Q, Liu J, Chen S, Liu J, Liu L, Liu G, et al. Caspase-12 is involved in stretch-induced apoptosis mediated endoplasmic reticulum stress. Apoptosis. 2016; 21(4):432-42. [DOI: 10.1007/s10495-016-1217-6] [PMID] 
This Page Intentionally Left Blank 